DOI: https://doi.org/10.18371/fp.3(39).2020.215154

УДК 338.24.021.8

\title{
ПРОМЫШЛЕННОСТЬ БЕЛАРУСИ: СТРУКТУРНАЯ ТРАНСФОРМАЦИЯ НЕИЗБЕЖНА
}

\author{
ЛИСОВСКИЙ Максим Иванович \\ кандидат экономических наук, дочент, \\ заведуюший кафедрой финансового менеджмента, \\ УО «Полесский государственный университет», Беларусь \\ e-mail:lisovsky.m@polessu.by
}

\author{
ЛИСОВСКАЯ Елизавета Максимовна \\ магистрант \\ УО «Полесский государственный университет», Беларусь \\ e-mail: lisaveta_fox_98@mail.ru
}

Анотація. 3 метою визначення напрямків розвитку промислового комплексу Республіки Білорусь проведено аналіз впливу макроекономічних чинників, визначено потенціал промисловості для формування у підприємств інноваційного типу поведінки, виявлено проблеми та надано рекомендащії щуодо їх усунення.

Ключові слова: промисловість, стратегія, інновація, макроекономічні фактори, потенціал розвитку, інвестиції.

Постановка проблемы. Необходимость структурной трансформации промышленной отрасли как основы экономического роста национальной экономики, необходимость исследования причин неэффективности деятельности белорусских промышленных предприятий и выявления направлений корректировки экономической политики в отношении предприятий промышленного сектора обуславливает актуальность темы данной статьи. Формально частные, но факти-
Аннотация. $B$ цчелях определения направлений развития промышленного комплекса Республики Беларусь проведен анализ влияния макроэкономических факторов, определен потенциал промышленности для формирования у предприятий инновационного типа поведения, выявлены проблемы и даны рекомендации по их устранению.

Ключевые слова: промышленность, стратегия, инновачия, макроэкономические факторы, потенцииал развития, инвестиции.

чески «огосударствленные» предприятия белорусской промышленности находятся под сильным влиянием государственного регулирования их деятельности. Функционирование неэффективного рынка капитала и труда, перераспределение ресурсов и регулируемые государством цены, не соответствующие реальным издержкам предприятий - все эти факторы создают благоприятные условия не для повышения эффективности деятельности предприятий, а наоборот, стиму- 
лируют рост бесхозяйственности и неэффективного использования ресурсов.

Анализ последних исследований и публикаций. Проблемам теории и практики управления предприятием, в том числе проблемам анализа, планирования и прогнозирования в монографической литературе, учебниках, периодической печати, научных исследованиях уделяется большое внимание в силу актуальности и значимости данных процессов, необходимых для эффективного функционирования предприятия. Значимые научные и прикладные исследования, посвященные проблемам экономического анализа, представлены в работах российских ученых: Г.В. Савицкой, Б.И. Герасимова, Т.М. Коноваловой, С.П. Спиридоновой, А.Д. Шеремета. Весомый вклад в развитие стратегического менеджмента внес М. Портер, разработавший методические основы конкурентного анализа. В работе А.С. Головачева, М.А. Головачевой и Н.В. Юровой проведен анализ методов прогнозирования стратегической конкурентоспособности экономики Республики Беларусь.

Проблемам определения экономического потенциала предприятия посвящены работы многочисленных исследователей, среди которых можно выделить представителей ресурсного подхода (С.Б. Барнгольц, Р.М. Игнатовский, Г.Б. Клейнер, В.Л. Тамбовцев, М.Ф. Тестина, Г.П. Соломко, Е.В. Шевченко, В.В. Ковалев), представителей результативного подхода (В.Н. Авдеенко, М.В. Афанасьев, И.Н. Богатая, Э.П. Горбунов), представителей целевого подхода (Р.А. Белоусов, К.М. Рахлин, Л.С. Сосненко, В. Штанский). Наиболее полной и структурированной является методика определения производственнофинансового потенциала П.А. Фомина и М.К. Старовойтова, дополненная Н.А. Мансуровой и Н.О. Шутяевой.

Цель статьи - исследование ключевых проблем, характерных для белорусских промышленных предприятий, выявление наиболее значимых факторов, препятствующих развитию промышленного комплекса и определение направлений его развития в рамках структурной трансформации экономики Республики Беларусь.

Изложение основных результатов. Для выработки стратегии развития промышленного комплекса в первую очередь необходимо определить отраслевую классификацию белорусской промышленности, определить ключевые характеристики и стратегические приоритеты по категориям отраслей.

Современные подходы к классификации отраслей достаточно подробно рассмотрены в работе И.С. Штаповой [5]. Достаточно важным, по мнению автора, особенно при формировании отраслевой политики, является выделение отраслей по приоритетности развития. Разделение отраслей белорусской промышленности по приоритетам развития на три блока определено в Программе развития промышленного комплекса Республики Беларусь. При этом необходимо отметить, что указанное там разделение отраслей на три блока не совсем подходит для разработки стратегии развития, так как характеристики отраслей, входящих в один блок, и соответствующие им приоритетные направления стратегического развития могут иметь значительные различия.

Анализ ключевых характеристик по отраслям промышленности Республи- 
ки Беларусь позволил сгруппировать

отрасли следующим образом (табл. 1).

Таблица 1

Группировка отраслей по основным отраслевым приоритетам

\begin{tabular}{|c|c|c|}
\hline Группа & Отрасли, входящие в группу & $\begin{array}{c}\text { Ключевые характеристики } \\
\text { группы }\end{array}$ \\
\hline Инновачионные & $\begin{array}{l}\text { - нано- и биотехнологии } \\
\text { - фармацевтика } \\
\text { - авиакосмические технологии } \\
\text { - информационно-коммуника- } \\
\text { ционные технологии } \\
\text { - радиоэлектроника } \\
\text { - микроэлектроника } \\
\text {-высокотехнологичное х химиче- } \\
\text { ское производство }\end{array}$ & $\begin{array}{l}\checkmark \text { требуют прямой господ- } \\
\text { держки, финансирования из } \\
\text { государственного бюджета в } \\
\text { рамках соответствующих } \\
\text { программ } \\
\checkmark \quad \text { характеризуются уника- } \\
\text { льностью продуктов } \\
\checkmark \quad \text { ориентированы на создание } \\
\text { новых рынков }\end{array}$ \\
\hline Традиционные & $\begin{array}{l}\text {-топливно-энергетический } \\
\text { плекс } \\
\text {-пищевая промышленность } \\
\text {-промышленность строительных } \\
\text { материалов }\end{array}$ & $\begin{array}{l}\checkmark \text { требуют компенсационной } \\
\text { государственной поддержки } \\
\checkmark \text { ориентированы на внутре- } \\
\text { нний рынок } \\
\checkmark \text { емкость внутреннего рынка } \\
\text { определяет минимально необ- } \\
\text { ходимый объем производства } \\
\checkmark \quad \text { обеспечивают } \\
\text { стратегическую безопасность }\end{array}$ \\
\hline Глобальные & $\begin{array}{l}\text { - химическая промышленность } \\
\text { - нефтеперерабатывающая про- } \\
\text { мышленность }\end{array}$ & $\begin{array}{l}\checkmark \text { ориентированы на мировой } \\
\text { рынок, } \\
\checkmark \text { не требуют государственной } \\
\text { поддержки }\end{array}$ \\
\hline $\begin{array}{l}\text { Инвестичионно- } \\
\text { привлекательные } A \\
\text { (специализирующиеся } \\
\text { на производстве тех- } \\
\text { нологически неслож- } \\
\text { ных продуктов) }\end{array}$ & $\begin{array}{l}\text { - металлургическое производство } \\
\text { - производство резиновых и } \\
\text { пластмассовых изделий } \\
\text { - текстильная и швейная про- } \\
\text { мышленность } \\
\text { - производство кожи, кожаных } \\
\text { изделий и обуви } \\
\text { - обработка древесины и пр-во } \\
\text { изделий из дерева }\end{array}$ & $\begin{array}{l}\checkmark \text { требуют точечных инвести- } \\
\text { ций в наиболее перспективные } \\
\text { проекты } \\
\checkmark \text { преимущественная ориен- } \\
\text { тация на экспорт продукции на } \\
\text { внешние рынки (около 60\% } \\
\text { реализованной продукции) } \\
\checkmark \text { ориентированы на отвоевы- } \\
\text { вание доли на «зрелых» } \\
\text { рынках }\end{array}$ \\
\hline $\begin{array}{l}\text { Инвестиционно- } \\
\text { привлекательные } \\
\text { (специализирующиеся } \\
\text { на производстве тех- } \\
\text { нологически сложных } \\
\text { многокомпонентных } \\
\text { продуктов) }\end{array}$ & $\begin{array}{l}\text { - транспортное машиностроение } \\
\text { - сельскохозяйственное и комму- } \\
\text { нальное машиностроение } \\
\text { - тяжелое машиностроение } \\
\text { - энергомашиностроение } \\
\text { - станкостроение }\end{array}$ & $\begin{array}{l}\checkmark \text { требуют значительных } \\
\text { финансовых вложений в } \\
\text { НИОКР и конструирование } \\
\text { изделий, в развитие } \\
\text { прикладных исследований. } \\
\checkmark \text { равноориентированы на } \\
\text { поставки продукции на внеш- } \\
\text { ние рынки и на внутренний } \\
\text { рынок РБ } \\
\checkmark \\
\text { вариентированы на отвоевы- } \\
\text { рание доли на «зрелых» }\end{array}$ \\
\hline
\end{tabular}

Источник: собственная разработка автора 
Для данного исследования в целях определения направлений развития промышленного комплекса наибольший интерес представляют инновационные и инвестиционно-привлекательные отрасли, которые должны стать центрами репродуцирования инноваций и способствовать формированию инновационного типа экономики, поэтому данные группы отраслей определены как приоритетные. Струк- турная трансформация экономики РБ должна начинаться с определения и устранения проблем и оценки возможностей в первую очередь в приоритетных отраслях.

С целью определения наиболее актуальных проблем был проведен анализ воздействия макроэкономических системных факторов по отраслям обрабатывающей (табл. 2).

промышленности

Таблица 2

Воздействие макроэкономических системных факторов по отраслям промышленности

\begin{tabular}{|c|c|c|c|c|c|c|}
\hline Отрасли/Факторы & $\begin{array}{l}\text { OBP } \\
-1\end{array}$ & $\begin{array}{l}\text { OBP } \\
-2\end{array}$ & $\begin{array}{l}\text { OBP } \\
-3\end{array}$ & $\begin{array}{l}\text { OBP } \\
-4\end{array}$ & $\begin{array}{l}\text { OBP } \\
-5\end{array}$ & УПЗ \\
\hline \multicolumn{7}{|c|}{ Инновачионные } \\
\hline пр-во электрооборудования & + & & + & + & & \\
\hline \multicolumn{7}{|c|}{ Традиционные } \\
\hline $\begin{array}{l}\text { производство электроэнер- } \\
\text { гии, газа и воды }\end{array}$ & + & & & + & + & + \\
\hline $\begin{array}{l}\text { производство пищевых про- } \\
\text { дуктов }\end{array}$ & + & + & & & + & \\
\hline целлюлозно-бумажное пр-во & + & & + & & + & \\
\hline $\begin{array}{l}\text { пр-во прочих неметалличе- } \\
\text { ских продуктов }\end{array}$ & + & & + & + & & \\
\hline \multicolumn{7}{|c|}{ Глобальные } \\
\hline химическое производство & + & + & & + & & + \\
\hline $\begin{array}{l}\text { производство нефтепродук- } \\
\text { тов }\end{array}$ & + & & & & + & + \\
\hline \multicolumn{7}{|c|}{ Инвестичионно-привлекательные $A$} \\
\hline $\begin{array}{l}\text { текстильное и швейное пр- } \\
\text { во }\end{array}$ & + & & + & + & & \\
\hline $\begin{array}{l}\text { пр-во кожи, кожаных изде- } \\
\text { лий и обуви }\end{array}$ & + & + & & & & \\
\hline $\begin{array}{l}\text { обработка древесины и пр-во } \\
\text { изделий из дерева }\end{array}$ & + & + & + & & & \\
\hline $\begin{array}{l}\text { пр-во резиновых и пластмас- } \\
\text { совых изделий }\end{array}$ & + & + & + & & & \\
\hline $\begin{array}{l}\text { металлургическое производ- } \\
\text { ство }\end{array}$ & + & & + & & & \\
\hline \multicolumn{7}{|c|}{ Инвестиционно-привлекательные Б } \\
\hline пр-во машин и оборудования & + & + & & + & & + \\
\hline $\begin{array}{l}\text { пр-во транспортных средств } \\
\text { и оборудования }\end{array}$ & + & & & & & \\
\hline
\end{tabular}

Источник: собственная разработка автора 
Плюсом отмечено присутствие влияния фактора на деятельность предприятий отрасли. Факторы указаны с использованием приведенной ранее классификации и деления на две группы: исходя из ограничений внутреннего рынка (OBP) и - из ограничений промышленных предприятий, ориентированных на внешние рынки (УПЗ).

В данной таблице установлены следующие обозначения и критерии оценки факторов:

ОВР-1 - фактор, обуславливающий давление поставщиков на предприятия отрасли, это зависимость кадровой политики промышленных предприятий от государственного регулирования рынка труда. Превышение темпа роста заработной платы над темпами роста производительности указывает на присутствие влияния данного фактора.

OBP-2 - нерыночная цена капитала, определяющая недостаток средств для финансирования инновационной активности. Критерием оценки служит соотношение затрат на технологические инновации с объемом продаж меньше среднеотраслевого значения 1,9 .

OВР-3 - фактор, обуславливающий давление покупателей на предприятия отрасли - это применение затратного подхода к формированию цен, который отражает ориентацию предприятий в большей мере на производство и в меньшей - на запросы покупателей. Критерием оценки служит значительное превышение объема производства над объемами продаж.

OBP-4 - присутствие государственной поддержки неэффективных предприятий. Определено на основании анализа расходов бюджета Республики Беларусь на национальную эконо- мику в разрезе государственных программ развития.

ОВР-5 - фактор, обуславливающий давление покупателей на предприятия отрасли - это присутствие в отрасли государственного регулирования цен (определенное законодательством).

УПЗ - установление принудительных заданий для эффективных предприятий на поставки продукции на внутренний рынок. Определено на основании опубликованных заявлений руководства предприятий. С целью оценки возможностей инновационного развития был проведен анализ его потенциала в отраслях обрабатывающей промышленности.

В табл. 3 приведены показатели, характеризующие потенциал отраслей промышленности для формирования у предприятий, входящих в эти отрасли, инновационного типа поведения.

Для характеристики отраслей были выбраны следующие показатели и критерии их оценки:

- интегральный показатель финансового состояния (ИПФС), рассчитанный в ходе проведенного исследования. Значение ИПФС от 1 до 2 баллов свидетельствует о высокой эффективности финансовой деятельности, 2-2,5 - эффективность средняя, выше 2,5 эффективность финансовой деятельности низкая.

- показатель высокотехнологичности отрасли (ПВО), \%. Если показатель высокотехнологичности отрасли имеет значение до $1 \%$ - степень инновационной активности низкая, от 1 до $3 \%$ - средняя, выше 3\% - инновационная активность высокая.

- прирост валовой добавленной стоимости (ПрВДС), \%. Прирост валовой добавленной стоимости до 10\% определен как нормальный, выше 10\% - 
высокий, и, соответственно, снижение валовой добавленной стоимости оценивается как негативное явление.

- удельный вес валовой добавленной стоимости в выпуске (ВДС/В), \%. Удельный вес добавленной стоимости в выпуске до $10 \%$ считается низкой,
10-40\% - средней, выше 40\% - высокой.

- темп роста объема продаж в долл. США, (ТрОП) \%. Рост объема продаж отрасли до $10 \%$ считается средним, выше 10\% - высоким, ниже 0\% - низким.

Таблица 3

Потенциал развития отраслей промышленности по категориям отраслей

\begin{tabular}{|l|c|c|c|c|c|}
\hline \multicolumn{1}{|c|}{ Отрасли/Факторы } & ИПФС & ПВО & ПрВДС & ВДС/В & ТрОП \\
\hline Инновационнье & & & & & \\
\hline пр-во электрооборудования & 1,8 & 2,3 & 16,1 & 33 & 4,4 \\
\hline Tрадиционные & & & & & \\
\hline производство электроэнергии, газа и воды & 2,6 & 0,36 & 9,5 & 33,9 & $-0,99$ \\
\hline производство пищевых продуктов & 2,6 & 0,42 & 46,4 & 23,7 & 17,2 \\
\hline целлюлозно-бумажное пр-во & 2,4 & 3,43 & 19,6 & 32 & $-1,2$ \\
\hline пр-во прочих неметаллических продуктов & 2,4 & 4,2 & 41,5 & 38,4 & 8,8 \\
\hline Глобальные & & & & & \\
\hline химическое производство & 2,2 & 1,79 & $-26,2$ & 45,1 & $-23,9$ \\
\hline производство нефтепродуктов & 3,2 & 2,24 & $-38,1$ & 7,8 & $-16,8$ \\
\hline Инвестиционно-привлекательные $A$ & & & & & \\
\hline текстильное и швейное пр-во & 2 & 2,18 & 15,2 & 41,4 & 8 \\
\hline пр-во кожи, кожаных изделий и обуви & 3 & 0,27 & 11,3 & 36,5 & 8 \\
\hline обработка древесины и пр-во изделий из дерева & 2,2 & 0,18 & 37,1 & 34,3 & 15,2 \\
\hline пр-во резиновых и пластмассовых изделий & 2,4 & 0,89 & 21,8 & 30,5 & 1,3 \\
\hline металлургическое производство & 2,2 & 1,76 & 5 & 23,7 & $-0,4$ \\
\hline Инвестиционно-привлекательные Б & & & & & \\
\hline пр-во машин и оборудования, в том числе: & 1,2 & 1,82 & 7,1 & 31,6 & $-4,9$ \\
\hline пр-во транспортных средств и оборудования & 1,8 & 4,95 & $-3,3$ & 23,6 & $-4,9$ \\
\hline
\end{tabular}

В табл. 3 низкий уровень значения показателя обозначен красным цветом, средний - желтым и высокий уровень показателя обозначается зеленым цветом.

Анализ воздействия макроэкономических системных факторов, анализ финансового состояния и потенциала инновационного развития приоритетных трех групп отраслей белорусской промышленности позволил выявить следующие проблемы и дать рекомендации по их устранению:

1. Отрасли инновационной группьы. Приоритетные направления стратеги- ческого развития: преимущественная ориентация на создание новых уникальных продуктов и их реализация на новых и быстрорастущих рынках.

Для отраслей инновационной группы (в связи с отсутствием данных для анализа в этой группе было рассмотрено только производство электрооборудования) характерно наличие таких макросистемных факторов, как зависимость кадровой политики промышленных предприятий от государственного регулирования рынка труда, ориентация на плановые задания, а не на спрос и высокая степень государ- 
ственной поддержки неэффективных предприятий.

Зависимость кадровой политики промышленных предприятий от государственного регулирования рынка труда и социально регрессивной конкуренции труда с невысокой производительностью и низкими доходами является фактором, имеющим всеобщий характер, действие которого распространяется на все отрасли промышленности. На необходимость устранения воздействия данного фактора неоднократно указывается различными авторами и аналитиками [2, $3,4]$. Решением данной проблемы является предоставление предприятиям полной и фактически действующей самостоятельности в выборе системы оплаты труда, устранение ведомственного контроля в области регулирования рынка труда и развитие внутрифирменных механизмов контроля соответствия заработной платы работника приносимому им доходу.

В целом же, в отраслях инновационной группы (на примере производства электрооборудования) воздействие указанных выше системных факторов является существенным, главным образом, ввиду того, что предприятия данной группы не выполняют своей главной функции: создание инновационных продуктов, позволяющих получать сверхприбыль. Об этом свидетельствуют показатели потенциала развития (табл. 3). При удовлетворительном значении интегрального показателя финансового состояния предприятий в отрасли по производству электрооборудования, значения показателей высокотехнологичности отрасли и прироста валовой добавленной стоимости здесь ниже, чем в некоторых отраслях традицион- ной группы. Также наблюдается невысокий по сравнению с другими отраслями рост объема продаж, что не характерно для инновационной группы. При выполнении инновационным предприятием указанных выше функций полученная от реализации сверхприбыль компенсирует высокие затраты на рабочую силу и импортное сырье. Выпуск новой продукции на быстрорастущих рынках при постоянно увеличивающемся спросе может быть не чувствителен к ценам, то есть действие указанных выше факторов нейтрализуется.

Существует несколько причин, определяющих текущее положение отраслей инновационной группы и невыполнение ими своих функций:

- отсутствие достаточного финансирования фундаментальных исследований в областях науки, соответствующих направлению развития данных отраслей;

- отсутствие механизмов взаимодействия научно-исследовательских организаций и конструкторских бюро, занимающихся прикладными исследованиями с предприятиямипроизводителями. То есть фактически, новшества и идеи разработчиков не могут стать промышленными инновациями, так как их интересы и возможности не согласуются.

- отсутствие необходимой для неэффективных на начальном этапе предприятий в инновационной группе государственной поддержки. Кроме незначительной доли бюджетных ассигнований на финансирование научно-технической и инновационной деятельности в Беларуси в целом, отдельно необходимо отметить низкую долю государственного участия в финанси- 
ровании НИОКР в отраслях инновационной группы $[5,6,7,8]$.

Таким образом, коренные трансформации в отраслях инновационной группы возможны при условиях:

- ускоренного технологического развития, которое связано, прежде всего, с созданием прочных связей прикладных исследований и производств.

- создания принципиально нового механизма государственного финансирования инновационных отраслей (по принципу венчурных фондов, когда финансирование осуществляется за счет «точечного» вливания в наиболее перспективные проекты).

Для группы инвестиционнопривлекательных отраслей воздействие внешних системных факторов различается с точки зрения наличия стратегических возможностей развития при производстве разных по степени технологической сложности продуктов.

2. Для отраслей, специализирующзихся на производстве технологически несложных продуктов (инвестициионн-привлекательные группь $A$ ), приоритетной является стратегия лидерства в издержках, поэтому воздействие факторов, препятствующих реализации данной стратегии, ощущается предприятиями этих отраслей сильнее.

Для этих отраслей (табл. 2) характерно сильное давление поставщиков как совокупное воздействие государственного регулирования рынка труда и высокой степени импортной зависимости. При этом для трех из них (текстильное и швейное производство, производство резиновых и пластмассовых изделий и металлургическое производство) характерна нечувствительность к ценам при выпуске про- дукции и ориентация на выполнение плановых заданий, а не на запросы потребителей. Присутствие влияния указанных факторов приводит к негативным последствиям.

Наиболее весомым фактором является способность реагировать на изменения спроса. Здесь невозможность сокращения издержек, ориентация на выполнение плановых целевых заданий и невнимание к изменениям запросов потребителей приводит к сокращению или потере доли рынка на значительных доходных сегментах.

Таким образом, в отраслях инвестиционно-привлекательной группы А наиболее существенное воздействие оказывают следующие факторы:

- существование механизмов оказания поддержки неэффективным предприятиям в ущерб поддержке развития перспективных предприятий на высокодоходных сегментах;

- существование механизмов, ограничивающих возможности сокращения расходов и препятствующих реализации стратегии абсолютного лидерства в издержках;

- сохранение на уровне управления ориентации на цену, а не на спрос при выпуске продукции.

Устранение или снижение негативного воздействия указанных факторов будет способствовать развитию предприятий данных отраслей.

3. Для отраслей, специализируюшихся на производстве технологически сложных многокомпонентных продуктов (инвестиционно-привлекательные группь Б), приоритетной является стратегия дифференциации, поэтому здесь сильнее воздействие факторов, определяющих качественные свойства производимых продуктов и возможности их продвижения. 
Дифференциация может осуществляться в разнообразных формах: по престижу дизайна или бренда, по технологии, по функциональным возможностям, по обслуживанию потребителей, по дилерской сети. Для отраслей белорусской промышленности, таких как производство машин, транспортных средств и оборудования, которые относятся к группе производств технологически сложных многокомпонентных продуктов, ключевым фактором, определяющим их неэффективное функционирование, является неверная конкурентная стратегия. Как было показано выше на примере тракторов приоритетная ориентация на низший ценовой сегмент в отраслях, где основное внимание покупателей сосредоточено на качестве продукции приводит к потере значительной доли рынка.

Кроме того, в сфере производства технологически сложных многокомпонентных продуктов, как и для отраслей инновационной группы, немаловажное значение имеет возможность финансирования инновационного развития предприятия. Для белорусских предприятий по производству машин, транспортных средств и оборудования неверная стратегическая ориентация в совокупности с недостатком финансовых ресурсов, необходимых для инвестирования в развитие, определяет наличие проблем в наиболее важных с точки зрения стратегического развития направлениях:

- по технологиям и функциональным возможностям основная проблема заключается в невозможности финансирования инновационных процессов на предприятиях машиностроения, что способствует их технологическому отставанию.
- по обслуживанию: значительные по сравнению с аналогами расходы на эксплуатацию продукции белорусского машиностроения также являются слабой стороной конкурентной позиции предприятий в этой отрасли.

Решением данной проблемы является поиск возможностей финансирования и привлечения инвестиций в отрасль, переориентация руководства предприятий на создание конкурентных преимуществ производимых продуктов для реализации стратегии дифференциации.

- по престижу дизайна или бренда: длительная ориентация на лидерство в издержках сформировала соответствующие представления покупателей и отношение к продукции белорусской машиностроительной отрасли, как к продукции низшей ценовой категории с невысокими потребительскими свойствами. При том, что лояльность потребителей к бренду снижает чувствительность к цене продукта, белорусские производители в отраслях машиностроения не стремятся к реализации этого конкурентного преимущества, о чем свидетельствуют показатели эффективности маркетинговой деятельности.

- по дилерской сети основным фактором, негативно воздействующим на развитие отраслей, специализирующихся на производстве технологически сложных многокомпонентных продуктов, является, как и для пищевой отрасли, ориентация на рынки стран постсоветского пространства. Отсутствие координации проводимых этими странами национальных промышленных политик приводит к появлению необоснованной конкуренции. 
Выводы. Таким образом, в отраслях инвестиционно-привлекательной группы, ориентированных на производство технологически сложной многокомпонентной продукции наиболее существенное воздействие оказывают следующие факторы:

- недостаток и нерациональное использование имеющихся денежных ресурсов, которые обуславливают технологическое отставание белорусских производителей от мировых лидеров и препятствуют инновационному развитию машиностроительных отраслей;

- неверная стратегическая ориентация руководства предприятий на лидерство в издержках при необходимо- сти фокусирования внимания на получении конкурентных преимуществ, необходимых для реализации стратегии дифференциации;

- сохранение барьеров для частных инвесторов, таких как требования по сохранению рекомендованного уровня занятости или выполнения социальных обязательств, установление планово-целевых заданий, несовершенство законодательных инструментов защиты прав частных инвесторов.

Таким образом, выполнение указанных рекомендаций будет первым шагом в направлении структурной трансформации экономики, способствующей экономическому росту.

\section{Список используемой литературы}

1. Штапова И.С. Современные подходы к классификации отраслей. Российское предпринимательство. 2008. № 12. Вып. 2 (125). С. 36-39.

2. Обзор по Беларуси. Всемирный банк : веб сайт. URL : http://www.worldbank.org/ru/country/belarus/overview (дата доступа : 10.09.2020). 3. Усоский В. Н. Национальная экономика Республики Беларусь : курс лекций для студентов высших учебных заведений / под общ. ред. В.В.Гаврилюка. Минск : МГЛУ, 2014. 284 с.

4. Мансурова Н.А., Шутяева Н. О. Методические основы оценки производственного потенциала промышленного предприятия. Экономические исследования. 2012. № 4. С. 49-55.

5. Ливенский В. М. Анализ состава и структуры доходов и расходов бюджета РБ. Современные аспекты экономики. 2020. № 4 (272). С. 190-195.

6. Ливенский В. М. Направления оптимизации государственных расходов в Республике Беларусь. Современные аспекты экономики. 2019. № 6 (262). С. $16-$ 22.

7. Экономика Беларуси : Размер номинального ВВП Беларуси. URL : http://www.ereport.ru/stat.php?razdel=country\&count=belarus (дата доступа : 10.09.2020). 
8. Официальный сайт Всемирного банка : веб сайт. URL : https://data.worldbank.org/indicator/NY.GDP.MKTP.CD?locations=BY (дата доступа : 10.09.2020). 